\title{
Egg and brood sizes of oceanic pelagic crustaceans
}

\author{
J. Mauchline \\ Dunstaffnage Marine Research Laboratory, Scottish Marine Biological Association, PO Box 3, Oban, Argyll PA34 4AD, United \\ Kingdom
}

\begin{abstract}
The eggs and broods of crustaceans that carry their embryos attached to their appendages or within a marsupium are examined. Larger crustaceans within an order or suborder have larger eggs than smaller crustaceans but the egg size relative to body size decreases except in 2 groups: the relative volume of the eggs of calanoid copepods and deep-living mysids is maintained at about $1.0 \%$ and $0.4 \%$ of body volume respectively across the ranges of size of the females examined. Brood volume relative to body volume tends to remain constant as body size increases and represents about 10 to $15 \%$ of body volume. The constraints on brood volume probably devolve from the possession of a rigid exoskeleton but some variation independent of body volume is possible. Egg size and number are dependent variables. Mysids, euphausids and decapods divide into species that produce large and those that produce small eggs. There may be a minimum viable size of egg. Consequently, small crustaceans may increase fecundity through production of successive broods whereas larger crustaceans can increase the number of eggs by decreasing egg size. The effect of increased lipid content of large eggs relative to an increase in egg size and incubation time is discussed.
\end{abstract}

\section{INTRODUCTION}

An examination of the eggs carried externally by many pelagic crustaceans suggests that there is a tendency for the deeper living ones to have larger eggs. A previous study of egg and brood sizes of a wide variety of mysid species (Mauchline 1973, 1980), all of which carry the newly fertilised eggs in a marsupium, showed that meso- and bathypelagic species have fewer and larger eggs than shallower living species. The number and size of the eggs varied between species and environments but the volume or weight of the brood remained relatively constant at approximately $10 \%$ of the body volume or weight of the parent female. Wittmann (1984) re-analysed these and additional data on mysids. Correlations between increasing body, egg and brood sizes and incubation periods on the one hand and increasing latitude and decreasing environmental temperature on the other hand were present. These interspecies relationships were highly correlated in coastal and epipelagic species but less significant or absent between species of deep-sea and high latitude epipelagic environments.

Herring (1974a) found that oceanic species of decapods also divided into 2 groups, one having large eggs of low density, the other having smaller eggs of greater density. There was no direct correlation with depth of occurrence of the species. He suggested that these 2 types of eggs might occur in other groups of crustaceans.

The egg and brood sizes of a variety of copepods, euphausiids, decapods and a few additional mysid species relative to the depths at which they live have been examined during the course of work on the fauna of the Rockall Trough and adjacent regions. These data provide a further insight into brood production in Crustacea.

\section{MATERIALS AND METHODS}

The principal source of deep-living meso-, bathyand benthopelagic crustaceans used in this investigation was the Rockall Trough, northeastern Atlantic Ocean. Additional species were obtained from the area to the south of the Rockall Trough in the northern part of the Bay of Biscay near $44^{\circ} \mathrm{N}, 13^{\circ} \mathrm{W}$. Supplementary data on species from elsewhere, especially Mysidacea, are also used.

Body volume of small organisms was measured using a Berardi apparatus (Berardi 1953). The volume of larger organisms was determined by blotting them dry and dropping them into appropriately sized measuring cylinders containing a known volume of water. Most species have spherical eggs but decapod crustaceans 
and a few species in other orders, such as the copepod Valdiviella insignis, have ellipsoidal eggs. The proportions of the eggs were measured and their volume calculated. Volume of ellipsoidal eggs is $1 / 3 \pi l r d$ where $l$ is the length and $r$ and $d$ the radius and diameter respectively.

\section{RESULTS}

\section{Egg size}

The majority of calanoid copepods in the samples that carried eggs in egg masses attached to the abdomen belonged to the family Euchaetidae. Only a few species belonging to other families were found to be ovigerous. They were classed as meso- to bathypelagic or as epipelagic according to the information given by Roe (1972) or oblained within samples from the Rockall Trough.

The 5 epipelagic species (Fig. 1) were too few in number to determine whether they have smaller eggs relative to their body size than the deeper living species. The largest species examined was Valdiviella insignis which has only 2 large eggs present; each egg is about $4 \%$ of the body volume of the female. Eggs of

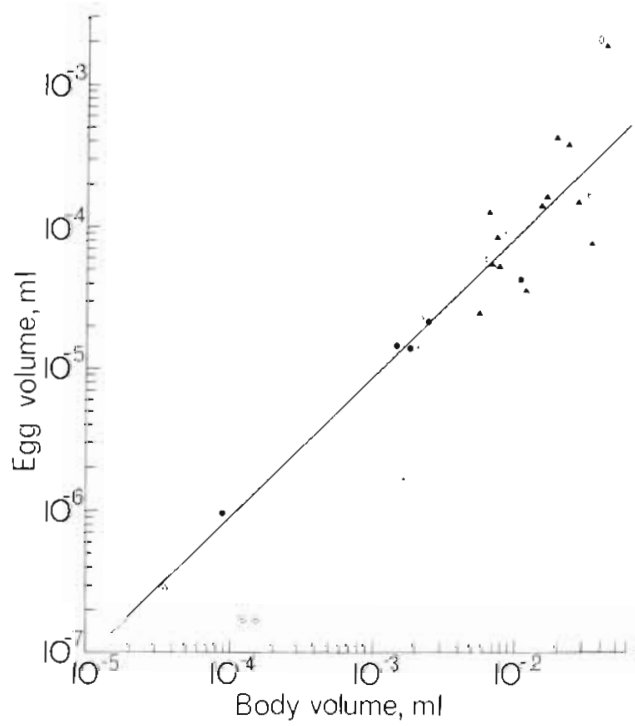

Fig. 1. Calanoid copepods. Egg volume plotted against female body volume. Species that lay their eggs freely into the environment $(\odot)$ are not included in the calculation of the regression line, the equation for which is given in Table 1. ( 1 ) Meso- to bathypelagic species; $(\bullet)$ epipelagic species. 1. Pseudocalanus elongatus; 2 , Euchaeta marina; 3, Pareuchaeta acuta; 4, P. media; 5, P. norvegicus; 6 , Euchirella messinensis; 7. E. bitumida; 8, Pseudochirella obtusa; 9, Pseudochirella sp.; 10. Valdiviella insignis; 11 , Pareuchaeta barbata; $12, P$. birostrata; 13, P. glacialis; 14, P. gracilis; 15, P. hanseni; 16, P. sarsi; 17, P. scotti; 18, Euaugaptilus magnus copepods average just under $1 \%$ of body volume but are as small as $0.23 \%$ in a species such as Pareuchaeta glacialis (Table 2). Eggs in this size range, 0.2 to $4.0 \%$ of body volume, are much larger than those of many species that lay their eggs freely into the environment (Fig. 1). The measurements of these latter eggs were obtained from McLaren (1966) and Kasahara et al. (1974).

The volume of the eggs in mysids was a cubic function of body length (Mauchline 1973, 1980). Body volume has since been determined in 16 species of mysids and is related to body length by the equation given in Table 1. Body length was measured as the distance between the base of the eyestalk and the posterior end of the telson and uropods, excluding the terminal setae. The 16 species selected were representative of the different body forms throughout the Mysidacea. This equation was used to convert the body length data on epipelagic species in the previous 2 publications to body volume. Data on an additional 7 bathy-or benthopelagic species are given in Fig. 2. The names of the other species in the analyses are given in Mauchline (1980, Table III).

The egg of small epipelagic and coastal mysids averages $4 \%$ of the body volume of the female but can be as high as $8.5 \%$ in Mesacanthomysis pygmaea, the smallest mysid examined (Fig. 2). Larger epipelagic species have smaller eggs relative to body size, those of $0.2 \mathrm{ml}$ volume (approximately $39 \mathrm{~mm}$ total length) having eggs that average $0.1 \%$ (range 0.02 to $0.27 \%$ ) of body volume. Mysis litoralis is exceptional; those of body volume $0.41 \mathrm{ml}$ (body length $35 \mathrm{~mm}$ ) have eggs representing $0.8 \%$ of body volume. The bathy- and benthopelagic species, on average, produce an egg about $0.4 \%$ of body volume. The slope of the regression line is 0.948 , and with additional data, may approach closer to unity. The volume of the egg produced by these species ranges between 0.1 and $2.0 \%$ of body volume

Eggs that are carried attached to the thoracic appendages of euphausiids and that are laid freely into the sea by other species have both been examined. Those laid freely into the sea are not always smaller, as in calanoid copepods, than those protected on the appendages. The eggs divide into 2 types (Fig. 3). The data on the eggs of Nematoscelis difficilis are from Nemoto et al. (1972) and of Thysanopoda minyops from Brinton (1987). The species with the larger egg relative to body size (Fig. 3) tend to be meso- to bathypelagic in habit. As with mysids, the slope $b$ of the regression line (Table 1) is greater for the deeper living species inferring that the larger egg has been actively selected for, even in species that lay their eggs freely into the sea. The volumes of the large and small eggs relative to the body volumes of the respective females are given in Table 2 
Table 1 Regression constants of the relation examined in the various groups of crustaceans

\begin{tabular}{|c|c|c|c|c|}
\hline \multirow[t]{2}{*}{ Organisms } & \multirow[b]{2}{*}{$n$} & \multicolumn{2}{|c|}{$\begin{array}{c}\text { Regression constants } \\
\log y=b \log x-a\end{array}$} & \multirow{2}{*}{$\begin{array}{c}\text { Value and } \\
\text { significance } \\
\text { of } r\end{array}$} \\
\hline & & a & $b$ & \\
\hline \multicolumn{5}{|c|}{ Egg volume (ml) on body volume (ml) } \\
\hline Calanoida & 18 & 2.055 & 1.003 & $0.912 \cdots$ \\
\hline \multicolumn{5}{|l|}{ Mysidacea } \\
\hline Epipelagic, coastal & 57 & 3.406 & 0.454 & $0.845^{\cdots}$ \\
\hline Bathy-, benthopelagic & 16 & 2.471 & 0.948 & $0.931 \cdots$ \\
\hline \multicolumn{5}{|l|}{ Euphausiacea } \\
\hline Epipelagic & 16 & 4.165 & 0.301 & $0.833^{\cdots} \cdots$ \\
\hline Meso-, bathypelagic & 9 & 2.715 & 0.695 & $0.962 \cdots$ \\
\hline \multicolumn{5}{|l|}{ Decapoda } \\
\hline Small eggs & 17 & 3.994 & 0.601 & $0.847^{\cdots} \cdots$ \\
\hline \multicolumn{5}{|c|}{ Brood volume (ml) on body volume (ml) } \\
\hline Calanoida & 18 & 1.378 & 0.823 & $0.913^{\cdots} \cdots$ \\
\hline \multicolumn{5}{|l|}{ Mysidacea } \\
\hline Epipelagic, coastal & 57 & 1.207 & 0.868 & $0.945^{\cdots}$ \\
\hline Bathy-, benthopelagic & 16 & 0.878 & 1.224 & $0.949^{\cdots}$ \\
\hline All species & 73 & 1.022 & 0.953 & $0.957^{\cdots} \cdots$ \\
\hline \multicolumn{5}{|l|}{ Euphausiacea } \\
\hline Egg-carriers only & 13 & 0.810 & 1.094 & $0.871 \cdots$ \\
\hline \multicolumn{5}{|l|}{ Decapoda } \\
\hline Acanthephyrasp. 2 & 15 & 1.266 & 1.148 & $0.878^{\cdots}$ \\
\hline Hymenodora glacialis & 9 & 0.710 & 2.397 & $0.620 \cdots$ \\
\hline Systellaspis debilis & 32 & 1.292 & 0.501 & $0.366^{\circ}$ \\
\hline Oplophorus spinosus & 15 & 1.059 & 0.688 & 0.335 \\
\hline Pandalus montagui & 32 & 0.679 & 0.804 & $0.833^{\cdots}$ \\
\hline Pandalus richardi & 8 & 1.140 & 2.044 & 0.678 \\
\hline Dichelopandalus bonnieri & 12 & 0.575 & 0.959 & $0.881^{\cdots}$ \\
\hline Crangon crangon & 43 & 1.021 & 0.800 & $0650^{\cdots} \cdots$ \\
\hline Crangon allmani & 5 & 1.034 & 1.237 & 0.798 \\
\hline All species & 45 & 1.043 & 0.981 & $0.937^{\cdots} \cdots$ \\
\hline \multicolumn{5}{|c|}{ Body volume (ml) on body length (mm) } \\
\hline Mysidacea & 16 & 4.840 & 2.883 & $0.987^{\cdots}$ \\
\hline$\cdot p<0.05 ; \cdots p<0.001$ & & & & \\
\hline
\end{tabular}

Table 2. Values of egg and brood volumes relative to female body volume. The mean value, as indicated by the regression analyses, often changes as shown by $\rightarrow$

\begin{tabular}{|c|c|c|c|c|c|c|}
\hline & \multicolumn{4}{|c|}{ Egg volume as a percentage of body volume } & \multirow{2}{*}{\multicolumn{2}{|c|}{$\begin{array}{c}\text { Brood volume as a percentage } \\
\text { of body volume }\end{array}$}} \\
\hline & \multicolumn{2}{|c|}{ Small eggs } & \multicolumn{2}{|c|}{ Large eggs } & & \\
\hline & Mean & Range & Mean & Range & Mean & Range \\
\hline Copepods & & & 1.0 & $0.2-4.0$ & $23 \rightarrow 8$ & $3-23$ \\
\hline Mysids & $4.0 \rightarrow 0.1$ & $0.02-8.5$ & 0.4 & $0.1-2.0$ & $20 \rightarrow 10$ & $2-50$ \\
\hline Euphausiids & $0.2 \rightarrow 0.01$ & $0.01-0.4$ & $0.8 \rightarrow 0.2$ & $0.1-2.5$ & $10 \rightarrow 18$ & $4-40$ \\
\hline Decapods & & $0.001-0.08$ & & $0.07-2.3$ & $10 \rightarrow 8$ & $3-31$ \\
\hline Ostracod & & & & 0.17 & 9 & \\
\hline Amphipods & & 0.06 & & 0.05 & & $13-14$ \\
\hline
\end{tabular}

The eggs of decapods that carry them attached to the abdominal appendages also divide into 2 groups, as Herring (1974a) found. The eggs which are larger relative to body size belong predominantly to meso-, bathy- and deep benthopelagic species (Fig. 4). The exception is the burrowing thalassinoidean Calocaris macandreae. The eggs that are smaller in size belong to a variety of epipelagic, shallow benthopelagic and 


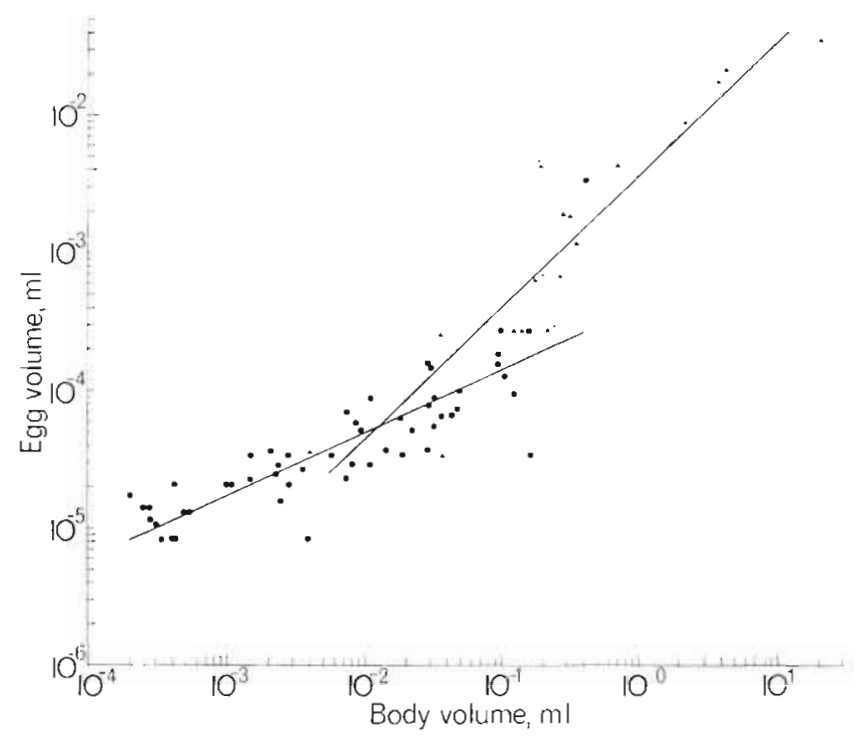

Fig. 2. Mysidacea. Egg volume plotted against female body volume. Equations of regression lines are given in Table 1. ( $\mathbf{\Delta}$ Meso-, bathy-, deep benthopelagic species; ( $\bullet$ ) epipelagic and coastal species. 1. Amblyops abbreviata; 2, Amblyopsoides ohlinii; 3, Antarctomysis maxima; 4, Boreomysis arctica; $5, B$. microps; 6, B. tridens; 7. Erythrops erythrophthalma; 8. Eucopia grimaldi; 9, E. unguiculata; 10, Gnathophausia gracilis; 11, G. ingens; 12, G. longispina; 13, G. zoea; 14. Lophogaster typicus; 15 . Mysidetes farrani

epibenthic species with some notable exceptions. Acanthephyra species are in this group and so distinct from other oplophorids which have larger eggs. Also, the largest decapod examined (Fig. 4) - the deep-living epibenthic crab Neolithodes grimaldi-has a small egg. The regression line for egg volume on body volume in species with the larger egg but of restricted range of

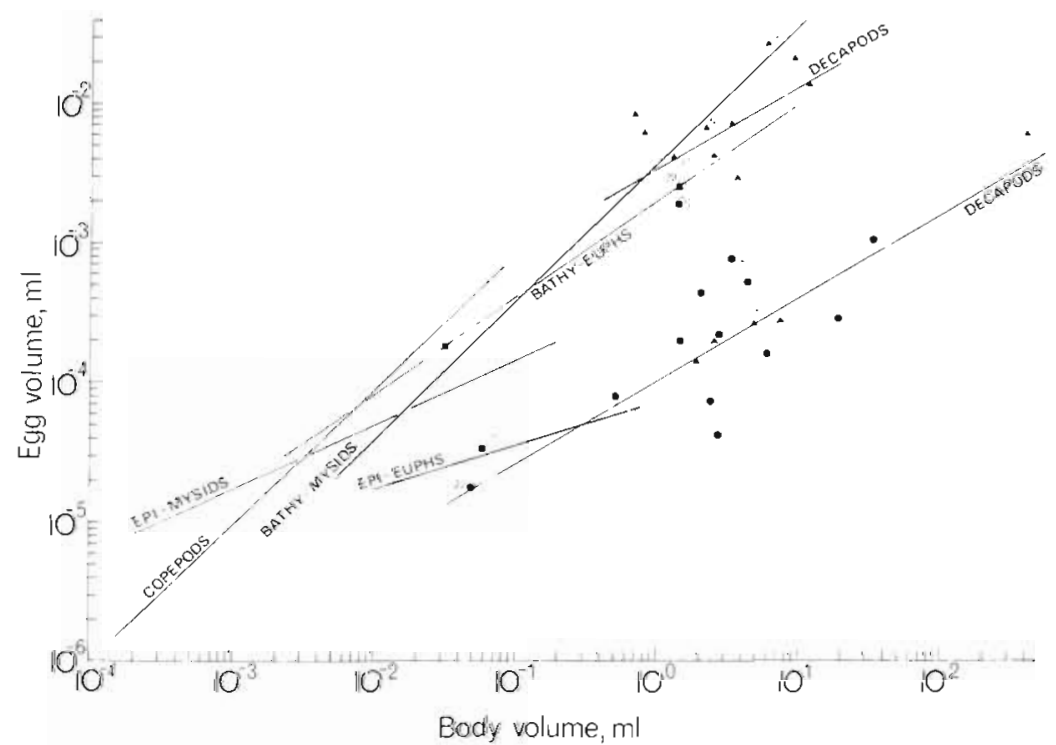

body volume is plotted but the coefficient is not significant at the $5 \%$ level. Part of the scatter in the results is because the eggs increase in size as they develop (Herring 1974a, b). The eggs of Systellaspis debilis measured here, for example, showed an increase in

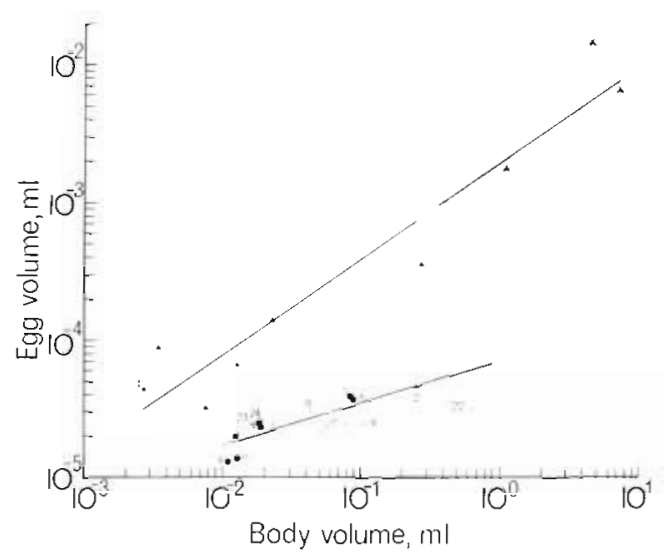

Fig. 3. Euphausiacea. Egg volume plotted against female body volume. Equations of regression lines are given in Table 1. ( $\mathbf{A}$, -) Meso- to bathypelagic and epipelagic species respectively that protect their eggs; $(\circlearrowleft, 0)$ those that release their eggs free in the sea. 1. Thysanopoda minyops; $2, T$ cornuta $; 3, T$ egregia; 4, Stylocheiron suhmi; 5, S. carinatum; 6, S. maximum; 7, S. elongatum; 8, S. longicorne; 9, Nematoscelis atlantica; 10, Nyctiphanes australis; 11, N. couchi; 12, N. capensis; $13, N$ simplex; 14 , Pseudeuphausia sinica; 15 , Nematoscelis difficilis; $16, N$. megalops $;$ 17, Euphausia eximia; 18, E. lucens; 19, E. pacifica; 20, E. superba; 21, E. triacantha; 22, Meganyctiphanes norvegica; 23, Thysanoëssa inermis; 24, T. raschi; 25, Nematobrachion flexipes

Fig. 4. Decapoda. Egg volume plotted against female body volume. Regression lines spanning the appropriate ranges of egg and body volume of the previous groups of organisms in Figs. 1 to 3 are also shown. Relative egg sizes of 2 amphipod and 1 ostracod species are also plotted for comparison. ( 4 Meso- to bathypelagic species and deep benthopelagic or epibenthic species; $(\bullet)$ epipelagic or shallow benthopelagic or epibenthic species; ( miscellaneous species. 1, Acanthephyra purpurea; 2, A. pelagica; 3. Acanthephyra sp. 1; 4, Acanthephyra sp. 2; 5, Ephyrina bifıda; 6, Hymenodora gracilis; 7. H. glacialis; 8, Systellaspis braueri; 9,5 . debilis; 10 . Oplophorus spinosus 11, Pasiphaea hoplocerca; $12, P$. sivado; $13, P$ multidentata; 14, Parapasiphaea sulcatifrons; 15. Spirontocaris Lilljeborgi; 16, Pandalus montagui; 17. P. richardi; 18. Dichelopandalus bonnieri; 19, Crangon crangon; 20, C. allmani 21, Pontophilus spinosus; 22, Philocheras bispinosus; 23. Uroptychus nitidus; 24, Munida bamffica; 25, Neolithodes grimaldi; 26, Geryon tridens; 27. Calocaris macandreae; 28, Nephrops norvegicus; 29, Gigantocypris muelleri; 30. Cyphocaris anonyx; 31. Parathemisto gaudicaudi 
their volume by a factor of 1.4 over the range found. There is, however, a significant relation between egg and body volume in species with a smaller egg (Table 1).

The bathymetric classification of decapods was obtained from Foxton (1970), Fasham \& Foxton (1979), Smaldon (1979) and Hargreaves (1984). The volumes of the eggs relative to body volume are given in Table 2 .

Eggs of the ostracod Gigantocypris muelleri are plotted in Fig. 4. They are equatable with those of the deeper living euphausiids and decapods. Among amphipods (Fig. 4) the meso- to bathypelagic species Cyphocaris anonyx has a relatively large egg while the epipelagic Parathemisto gaudicaudi has a smaller egg relative to its body size. The relative volumes of these eggs are also given in Table 2.

\section{Brood size}

The numbers of eggs contained in the egg masses attached to the various crustaceans were counted and the volume of the broods computed. Among the calanoid copepods, the 4 euchirellid species form a group with smaller than average broods relative to body volume (Fig. 5). Broods are equal to about $25 \%$ of body volume in small copepods and decrease to about

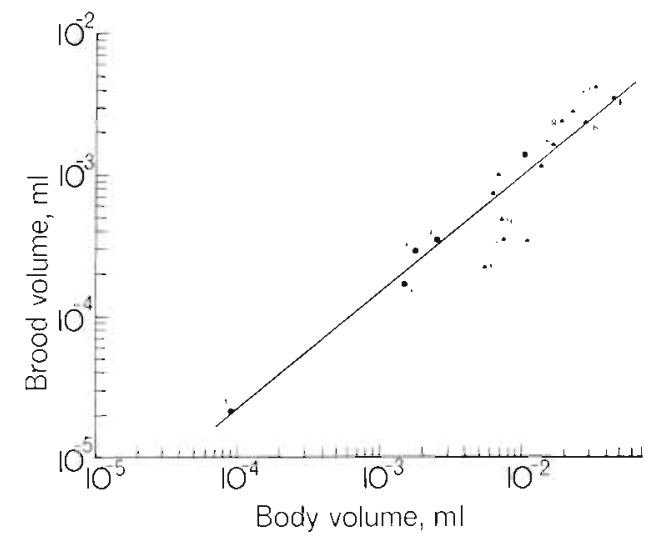

Fig. 5. Calanoid copepods. Brood volume related to body volume in species that carry their eggs. Equation of regression line is given in Table 1. Species are numbered as in Fig. 1

$8 \%$ of body volume in large species (Fig. 5; Table 2). The euchirellids have broods of 3 to $5 \%$ body volume while that of Pareuchaeta glacialis is about $13 \%$.

The brood sizes of the mysids were obtained from data given by Mauchline (1980) and new data on deeper living species as described above (Fig. 6). Regression equations were calculated for epipelagic and coastal species on the one hand and bathy- and deep-living benthopelagic species on the other (Table 1). Smaller, shallow-living species have relatively larger broods, representing about $20 \%$ of body volume,

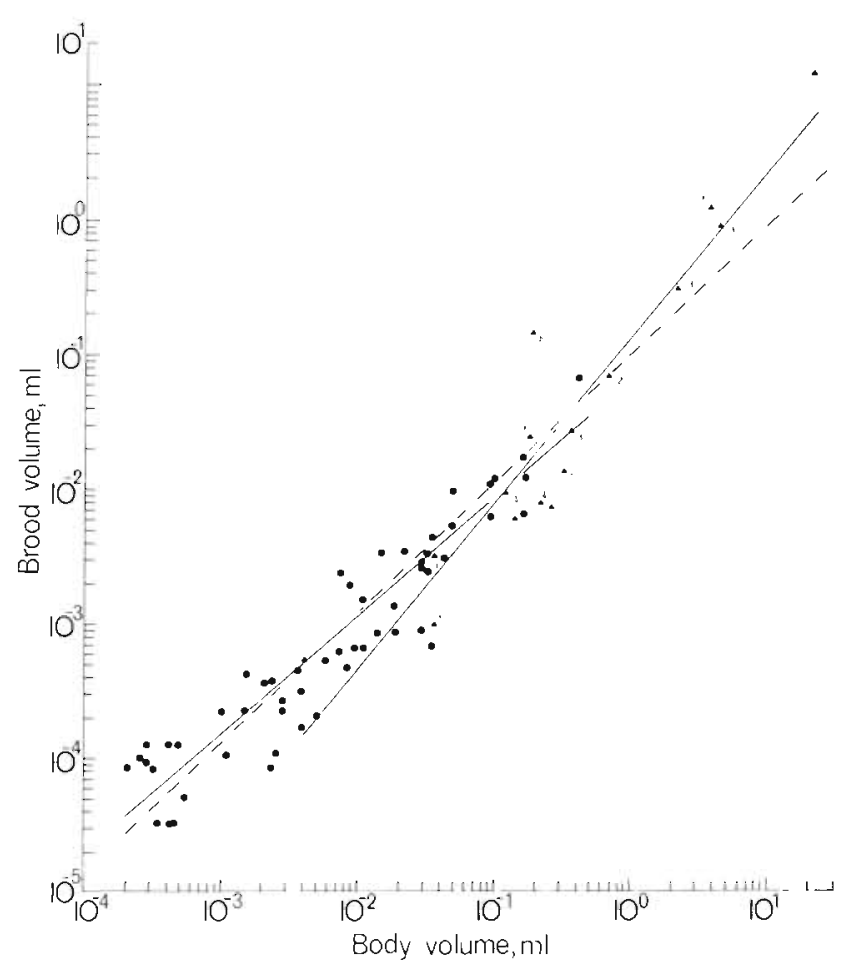

Fig. 6. Mysidacea. Brood volume related to body volume, Equations for the 3 regression lines are given in Table 1. Species are numbered as in Fig. 2. The dashed regression line is for all species

while large shallow-living species have broods of about $10 \%$ body volume (Table 2 ); the ranges in brood sizes are 8 to $43 \%$ and 2 to $20 \%$ respectively. The slope of the regression line for bathy- and benthopelagic species is greater than unity inferring that larger broods are produced by larger species. That of the largest mysid, Gnathophausia ingens, approximates $50 \%$ of the body volume but this is probably an overestimate as discussed later.

The broods of euphausiids that carry their eggs are shown in Fig. 7 along with those of 2 Thysanopoda species that lay their eggs freely into the sea. As in copepods, there is no obvious distinction between the broods of shallow and deep living species. The slope of the regression is greater than unity so that larger species tend to produce larger broods (Table 2). The brood of Stylocheiron longicorne is exceptional, being about $40 \%$ of body volume. The average brood of smaller euphausiids is about $10 \%$ while that of large species is about $15 \%$.

Brood sizes within species of decapods are related to body size. The size of the egg, however, does not vary with the body size of the female but is much more constant. Regression equations for several species are given in Table 1 and Fig. 8 . There is no obvious distinction between the sizes of broods of shallower and deeper living species (Fig. 8). The regression equations 


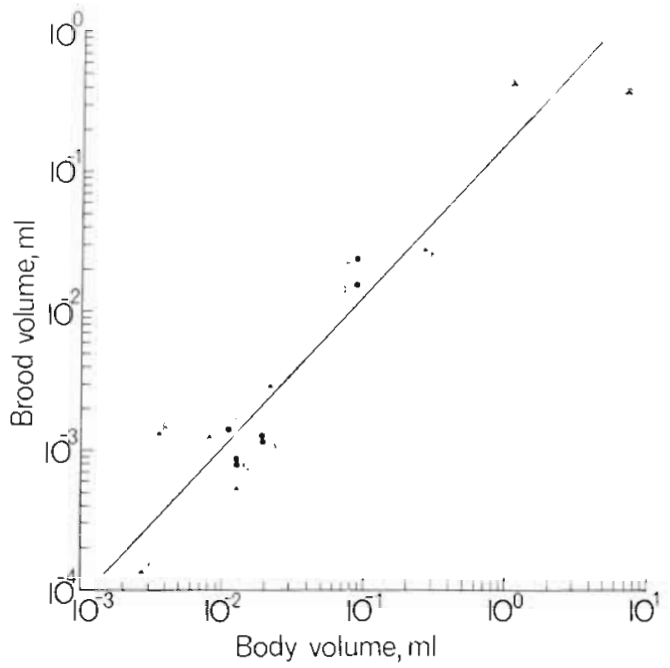

Fig. 7. Euphausiacea. Brood volumes of species that carry their eggs. Equation of regression line is given in Table 1. The broods of Thysanopoda egregia and $T$. minyops are also plotted but not included in the regression equation. Species are numbered as in Fig. 3

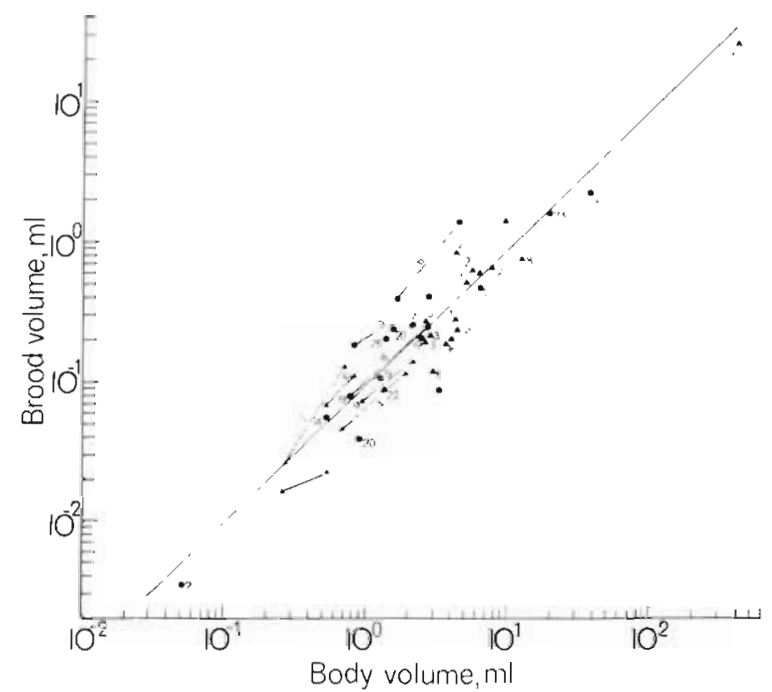

Fig. 8. Decapoda. Brood volume related do body volume. Equations of regression lines for individual species and that for all decapods are given in Table 1 . Species are numbered as in Fig. 4

for total mysid and decapod species are not significantly different

\section{DISCUSSION}

The calanoid copepods examined here are dominated by those belonging to the family Euchaetidae. There is no evidence of there being a dichotomy in egg size among the species carrying eggs. Corey (1981) examined 18 species of Cumacea; their eggs show a continuous range of size even when those of the deepsea species Leucon jonesi, described by Bishop (1982), are included. The data reviewed by Nelson (1980) are not conclusive for the Amphipoda. There are, indeed, species with larger eggs - Cyphocaris anonyx examined here being one - but there is a more or less continuous range. Measurements of more species from the deep-sea and high latitude environments are required before any distinct dichotomy can be demonstrated. Similarly, no dichotomy is present in the size of newly released juveniles of 25 species of Isopoda (Luxmoore 1982). In contrast to these groups, a marked division into small and large eggs exists in the Mysidacea, Euphausiacea and Decapoda (Figs. 2 to 4).

In general, larger sized species of crustaceans have larger eggs. This is true of Cumacea (Corey 1981), Amphipoda (Nelson 1980), Isopoda (Luxmoore 1982) and in the groups examined here. The relative size of the egg, that is as a proportion of body size, decreases within all these groups with increasing body size except within calanoid copepods and meso- to bathypelagic mysids where it tends to remain constant. This is reflected by the exponents $b$ of the equations for egg size on body size in Table 1 . The exponents are also less than unity in the data of Corey (1981) and Nelson (1980) for Cumacea and Amphipoda. Thus smaller species of crustaceans tend to have relatively larger eggs than larger species.

Brood volume is the product of egg number and volume. The exponents of body volume in the equations relating brood to body volume in Table 1 are close to unity and infer that reproductive effort per brood tends to be a standard proportion, 10 to $15 \%$, of body volume or weight. The exponent in Cumacea for brood on carapace volume is 0.814 as calculated from data in Corey (1981) and in Amphipoda is 0.880 for brood volume on body length raised to the third power (data in Nelson 1980); both relations are significant at the $0.1 \%$ level.

Thus brood size is constrained by body size and flexibility primarily introduced by the then dependent variables of egg size and number. The options open to small crustaceans are, therefore, more limited than those available to larger animals. There may be a minimum viable size of egg or this may be a reflection in the egg of a minimum viable size of the resultant larva. In consequence, the potential numbers of eggs that small crustaceans can produce within a single brood is limited. Increased fecundity is then dependent on the production of multiple broods. Childress \& Price (1978) compared the production of eggs in the large mysid (151 $\mathrm{mm}$ total length) Gnathophausia ingens with that in the small mysid $(5.3 \mathrm{~mm}$ length) Metamysidopsis elongata. The former produces a single brood of 150 to 350 eggs while the latter produces some 14 or more broods totalling about 340 eggs. 
There is no strict correlation between the occurrence of relatively large sized eggs and the deep-sea and high latitude environments. Many species that do inhabit these environments are larger in body size and have relatively large eggs. This is especially emphasized in the euphausiids, mysids and decapods. There are, however, exceptions such as the acanthephyrid decapods. Wittmann (1984) points out that, in the case of mysids, species with large eggs are often semelparous while those with small eggs are interoparous. There is only evidence (Childress \& Price 1978) of semelparity in Gnathophausia ingens. The congener $G$. zoea is probably not semelparous (Mauchline 1986) but capable of producing 2 broods. A brood volume of $G$. ingens estimated as about $50 \%$ body volume by Childress \& Price seems high. Their lower estimate of 200 eggs per brood results in a brood volume equal to about $30 \%$ of body volume. This is about twice the modal crustacean value and may be a contributable factor towards adoption of semelparity. Brood volumes of $G$. zoea are 15 to $20 \%$ of body volume (Fig. 6) and may not be enough to warrant semelparity.

The data in Fig. 4 infer that there are 2 general types of eggs in crustaceans; a small egg is represented by those of the epipelagic euphausiids and a mixed group of decapods while a large egg is represented by those of the other groups. Copepods that release their eggs freely into the water (Fig. 1) lie on an extrapolation of the line for the mixed group of decapods with the small egg. The division between the small and large egg carriers is obscured in the smaller crustaceans where considerable overlap among groups exists (Fig. 4). Further overlap in these size classes would be introduced if accurate transformations to a volume basis of Nelson's (1980) data on amphipods and Corey's (1981) data on cumaceans were available and would be further compounded by data on very small crustaceans such as cyclopoid and harpacticoid copepods.

The larger eggs have a relatively high lipid content compared with smaller eggs. Herring (1974a) considers this to be linked with abbreviated development in species with larger eggs; a more advanced larva hatches from large eggs. Incubation times relative to egg size have been examined by Steele \& Steele (1975). Extrapolation of their data on eggs of 0.2 to $1.8 \mathrm{~mm}$ size overestimates incubation times of eggs of 2.0 to $4.0 \mathrm{~mm}$ size reported by Herring (1974b) for several decapod species and by Childress \& Price (1978) for the mysid Gnathophausia ingens. Wittmann (1984) considers that increased egg size contributes less to increased incubation times than the decreased environmental temperatures to which these larger eggs are subjected. The increased lipid store in these large eggs requires an increased size of egg to accommodate it but may not contribute proportionally to increased incubation time. Herring (1974b) goes as far as suggesting that the large eggs may have a fundamentally different embryonic metabolism. The discontinuity in the ranges of relative egg size in mysids, euphausiids and decapods (Figs. 2 to 4 ) could imply differences in the metabolic processes of the females in production of small and large eggs.

Acknowledgement. The Dunstaffnage Marine Research Laboratory of the Scottish Marine Biological Association is financed by the Natural Environmental Research Council, London.

\section{LITERATURE CITED}

Berardi, G. (1953). Apparecchio per una precisa valutazione volumetrica di campioni di plancton. Mem. Ist. ital. Idrobiol. 7: 221-228

Bishop, J. D. D. (1982). The growth, development and reproduction of a deep sea cumacean (Crustacea:Peracarida). Zool. J. Linn. Soc. 74: 359-380

Brinton, E. (1987). A new abyssal euphausiid, Thysanopoda minyops, with comparisons of eye size, photophores, and associated structures among deep-living species. J. Crust. Biol. 7: 636-666

Childress, J. J., Price, M. H. (1978). Growth rate of the bathypelagic crustacean Gnathophausia ingens (Mysidacea : Lophogastridae). I. Dimensional growth and population structure. Mar. Biol. 50; 47-62

Corey, S. (1981). Comparative fecundity and reproductive strategies in seventeen species of the Cumacea (Crustacea : Peracarida). Mar Biol. 62: 65-72

Fasham, M. J. R., Foxton, P. (1979). Zonal distribution of pelagic Decapoda (Crustacea) in the eastern North Atlantic and its relation to the physical oceanography. J. exp. mar. Biol. Ecol. 37 225-253

Foxton, P. (1970). The vertical distribution of pelagic decapods (Crustacea : Natantia) collected on the SOND cruise 1965. I. Caridea. J. mar biol. Ass. U. K. 50: 939-960

Hargreaves, P. M. (1984). The distribution of Decapoda (Crustacea) in the open ocean and near-bottom over an adjacent slope in the northern North-east Atlantic Ocean during autumn 1979. J. mar. biol. Ass. U. K. 64: 829-857

Herring, P. J. (1974a). Size, density and lipid content of some decapod eggs. Deep Sea Res. 21: 91-94

Herring, P. J. (1974b). Observations on the embryonic development of some deep-living decapod crustaceans, with particular reference to species of Acanthephyra. Mar. Biol. 25: 25-33

Luxmoore, R. A. (1982). The reproductive biology of some serolid isopods from the Antarctic. Polar Biol. 1: 3-11

Kasahara, S., Uye, S., Onbe, T (1974). Calanoid copepod eggs in seabottom muds. Mar Biol. 26: 167-171

McLaren, I. A. (1966). Predicting development rate of copepod eggs. Biol. Bull. mar. biol. Lab., Woods Hole 131: 457-469

Mauchline, J. (1973). The broods of British Mysidacea (Crustacea). J. mar biol. Ass. U. K. 53: 801-817

Mauchline, J. (1980). The biology of mysids and euphausiids. In: Blaxter, J. H. S., Russell, F. S., Yonge, C. M. (eds.) Advances in marine biology, Vol. 18. Academic Press, New York, p. 1-369

Mauchline, J. (1986). The biology of the deep-sea species of 
Mysidacea (Crustacea) of the Rockall Trough. J. mar biol Ass. U. K. 66: 803-824

Nelson, W. G. (1980). Reproductive patterns of gammaridean amphipods. Sarsia 65: 61-71

Nemoto, T., Kamada, K., Hara, K. (1972). Fecundity of a euphausiic crustacean, Nematoscelis difficilis, in the North Pacific Ocean. Mar. Biol 14: 41-47

Nemoto, T., Brinton, E., Kamada, K. (1977). Reproduction and growth of deep sea Thysanopoda euphausiids. Bull. Plankton Soc. Jap. 24: 36-43

Roe, H. S. J. (1972). The vertical distributions and diumal migrations of calanoid copepods collected on the SOND cruise, 1965. I. The total population and general discussion. J. mar. biol. Ass. U. K. 52: 277-314

Smaldon, G. (1979). British coastal shrimps and prawns. In: Kermack, D. M., Barnes, R. S. K. (eds.) Synopses of the British fauna, No. 15. The Linnean Society, London

Steele, D. H., Steele, V J. (1975). Egg size and duration of embryonic development in Crustacea. Int. Rev. ges. Hydrobiol. 60: 711-715

Wittmann, K. J. (1984). Ecophysiology of marsupial development and reproduction in Mysidacea (Crustacea). Oceanogr. mar Biol. A. Rev. 22: 393-428

This article was submitted to the editor; it was accepted for printing on January 27, 1988 